\title{
Some Considerations about the Rotating Cell Structure
}

\author{
Franco Nurzia, Chiara Palomba, and Pierpaolo Puddu \\ Mechanical Engineering Department, University of Cagliari, Piazza D’armi, 09123 Cagliari, Italy \\ Correspondence should be addressed to Chiara Palomba, palomba@iris.unica.it
}

Received 31 May 2009; Accepted 5 August 2009

Recommended by Yutaka Ohta

Rotating stall instability in axial flow compressors arises when the mass flow is reduced at constant rotational speed. Despite the number of experimental and theoretical work already published in the scientific literature, many questions still remain unanswered. A complete model that could be of help both in the design process and in the modelling process of existing engines is not yet available. A fundamental research program has been carried out at the Department of Mechanical Engineering of the University of Cagliari with the scope of reaching a better understanding of the basic flow field structures and of the global performance in stall. The cinematic structure of the cell during abrupt full 1-cell stall in a two-stage axial flow compressor with IGV has been analysed with the aid of hot-wire anemometer and of a total pressure probe. The results have revealed interesting features about the cell flow structures and their variations along the stalled performance branch of the compressor. The present paper aims at pursuing further the flow analysis including the investigation of upstream flow field. Therefore, the inlet duct has been extended to perform the measurements. The complete flow field measurements will allow to obtain a complete cinematic description of the cell.

Copyright ( 2009 Franco Nurzia et al. This is an open access article distributed under the Creative Commons Attribution License, which permits unrestricted use, distribution, and reproduction in any medium, provided the original work is properly cited.

\section{Introduction}

Rotating stall in axial flow compressors has been studied since the early 50 s when it was firstly recognised as a separate instability from surge. Since then, there has been an intensive experimental and theoretical research activity which investigated different aspects of this complex phenomenon. Regardless its apparent simplicity and repeatability for a given compressor many questions about it still remain unanswered. In this paper the issue of the structure and motion of a full-span rotating stall cell is addressed and in this introduction a brief description is made of the main models and interpretations found in the scientific literature published in the last almost 60 years. Without being exhaustive one may summarise three main concepts formulated about the nature, structure, and motion of a cell: for the structure Fabri and Siestrunck [1], Day and Cumpsty [2], and Seidel [3], while for the cell motion Emmons et al. [4], Moore [5], and Moore and Greitzer [6].

When abrupt rotating stall that arises the flow in the compressor is no longer axisymmetric, regions of perturbed flow are found rotating around the compressor at an approximately constant speed usually lower than rotor speed. The consequences on the performance of the compressor are such that the pressure coefficient is strongly reduced and the operative point now moves on a new branch of performance curve. This phenomenon presents hysteresis and recovery is usually reached for a much greater flow coefficient with respect to peak of performance curve.

Emmonset al. [4], considered the cell as a region of separated flow which is formed on one blade when it reaches the stalling condition. This region enlargers until its size is sufficiently large to influence the incoming flow. This incoming flow would then deviate from its unperturbed direction so that while trying to flow around the obstruction it would cause increased incidence for the following blades and reduced incidence for the preceding blades so that the former would enter stall while the latter would unstall. As a consequence, the stall condition will propagate in direction opposite to rotor rotation, while in the absolute reference frame, it will propagate in the same rotor direction but at a lower speed. This first hypothesis gave rise to a series of stall models based on the stalling behaviour of blade profiles and of blade channels.Fabri and Siestrunck [1] presented 
a model in which the cell was seen as a region with zero axial velocity component like a rotating fluid bluff body. However, the experimental results by Das and Jiang [7], Breugelmans and Mathioudakis [8], Palomba et al. [9], Nurzia et al. [10] have revealed that abrupt one-cell stall may present complex flow structures and that the mechanism of cell rotation and the type of interaction among the different flow regions are not evident. Day and Cumpsty [2] after an extensive experimental investigation of rotating stall in several compressors with different design point proposed the active cell model in which the clean flow would move in the tangential direction passing through the cell. This idea came from the observation that in between blade rows of a multistage compressor during rotating stall the flow in the perturbed region presents very high values of tangential velocity component higher than cell speed. The idea of the active cell was thought also to explain why the cell extends axially through the compressor while if the cell was passive it should present a pattern inclined along the axial direction; see Figure 1. This innovative model was not completely agreeing with the more recent works by Breugelmans and Mathioudakis [8] and Das and Jiang [7]. In these works, the tangential crossing of the clean flow is not in accordance with the velocity diagrams at the cell borders, nevertheless, the cell structure is far from being a dead wake region.

It was felt that more fundamental research was needed to reach a better understanding of the underlying stall cell dynamics and to make future improvements in stall modelling. Since several years a research project started at the Department of Mechanical Engineering of the University of Cagliari aiming at a better understanding of rotating stall phenomenon in axial flow compressors. Hot-wire probes with the multirotation technique for the determination of the three dimensional flow field during rotating stall have been used on a single rotor, single stage, and twostage compressor. The experimental results in a single rotor (Palomba et al. [9]) and in a two-stage compressor (Nurzia et al. [10]) show velocity components that are in agreement with the ones of Breugelemans and Mathioudakis and Das and Jiang thus supporting the idea that tangential crossing of clean flow is not possible. Later, Puddu et al. [11] through velocity and wall static pressure measurements identified different flow structures in the cell flow region for a twostage low-speed axial flow compressor presenting singlecell abrupt rotating stall; see Figure 1. The cell border regions IR called "interface" regions are characterised by high circumferential velocity gradients. A wide portion of the cell is characterised by high tangential and low axial flow component and constant static pressure equal to inlet total pressure extending axially over the whole compressor; this has been called SF "stalled flow region." A third region $\mathrm{BF}$ is characterised by a strong and organised back flow that crosses the compressor from downstream to upstream following quite well the direction of the blades and presenting static pressure changes along the axial direction, this region has been called "back flow region." In order to complete the description of the cell structure and try to better understand the active/passive characteristic of the cell, in the present paper the three-dimensional flow measurements
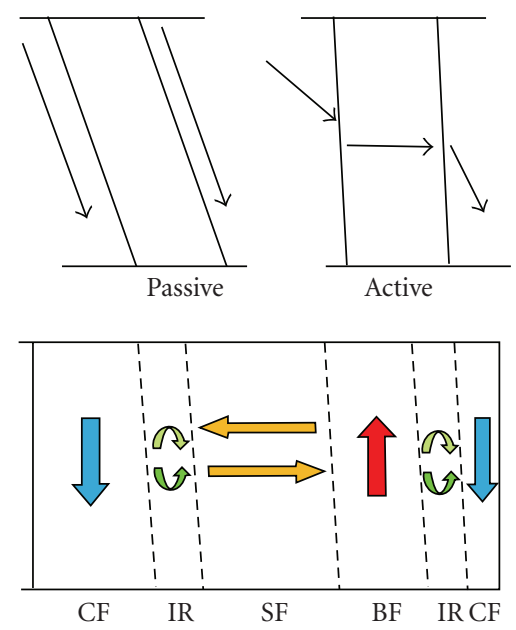

FIGURE 1: Different cell structures (CF: clean flow, IR: interface region, SF: stalled flow, and BF: back flow).

and total pressure measurements have been extended to the region upstream of the IGV of the two-stage axial flow compressor.

\section{Description of the Two-Stage Compressor's Test Facility}

The axial flow compressor under investigation consists of two identical stages. Both rotors and stators consist of 32, C4 profile blades. The rotor and stator blades of constant chord are twisted with profiles stacked upon their centre of gravity for the rotor and the blade Trailing Edge for the stator as shown in Figures 2(a) and 2(b), while the bladeto-blade plane at midspan is shown on Figure 2(c). The compressor's hub-to-tip ratio is 0.667 and the tip diameter is $0.381 \mathrm{~m}$. Figure 2 (c) shows the blade-to-blade Section of the compressor including the inlet guide vane which is composed of 23 blades with symmetric profiles and chord of $0.0435 \mathrm{~m}$. The compressor operates in the test facility represented in Figure 3, designed and built at the Department of Mechanical Engineering of the University of Cagliari to allow the determination of compressor performance curve according to ISO CD 5801. The global performance compressor parameters have been determined according to the standards measuring the pressures at the given points in the test tunnel with the aid of a Betz micromanometer. More details about test facility and procedure may be found in [10] by Nurzia et al. (2000) and [11] by Puddu et al. (2001). The performance curve is shown in Figure 4. The compressor exhibits abrupt full-span one-cell rotating stall. The cell rotates at approximately $32 \%$ of rotor speed; however the cell frequency is not constant along the stalled performance curve. The new measurement campaign aimed at the determination of the flow conditions upstream of the IGV. Therefore, the inlet has been modified by installing a straight duct of $300 \mathrm{~mm}$ with 5 measuring sections ready to allow radial probe insertion and with 8 static pressure taps equally spaced in the circumferential direction. The position 


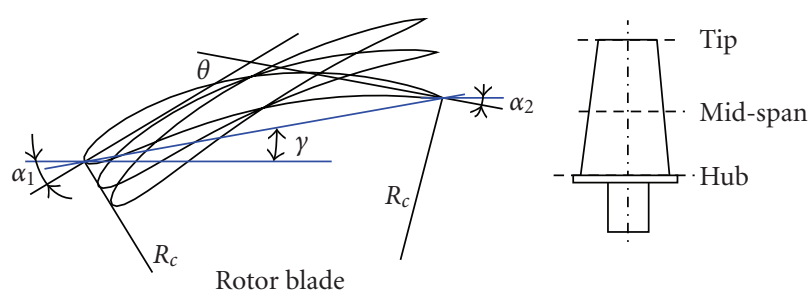

(a) Rotor blade stacking

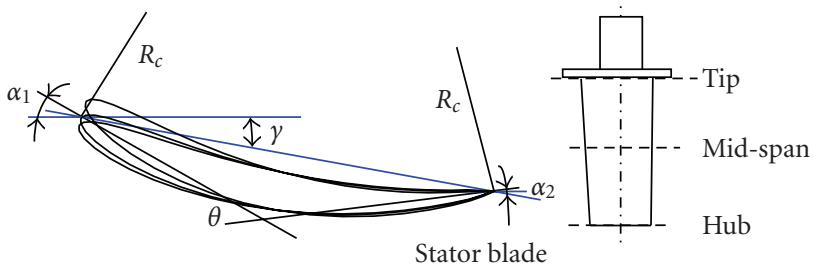

(b) Stator blade stacking

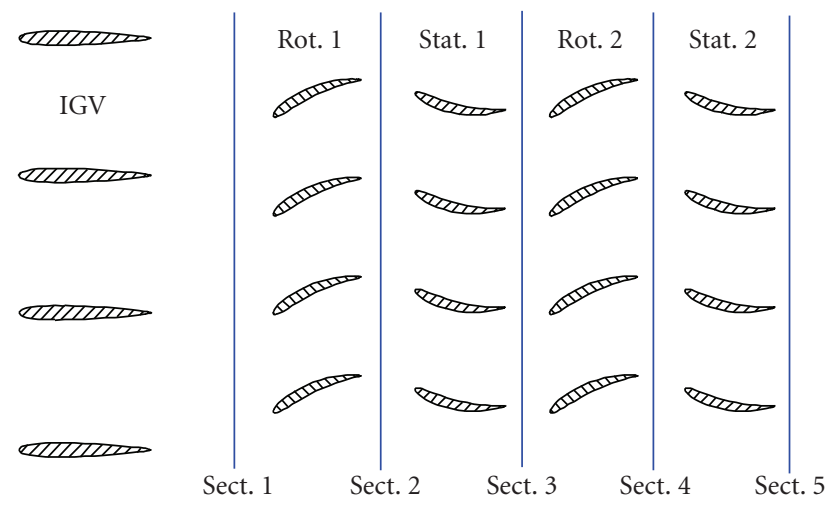

(c) Compressor blade rows at midspan

Figure 2

of the new measuring sections is shown in Figure 3. The tests will be made in section e which is located $36 \mathrm{~mm}$ upstream of the previous inlet section characterized by the letter I in the sketch.

\section{Description of Test Conditions and Measurement Technique}

Tests have been conducted at a rotational speed of $1500 \mathrm{rpm}$ for point P2 of Figure 4 on the hysteresis branch of stalled performance curve just before recovery of stable operation. The flow and pressure fields have been measured using a single slanted hot wire anemometer and a $4 \mathrm{~mm}$ cylindrical pressure probe with a single pressure tap and a pressure transducer having a resonant frequency of $1 \mathrm{kHz}$. The investigated sections are e, 1, 2, 3, 4, 5, 7, 8, 12 shown in the sketch of Figure 3 . For each section and for each radial and axial position investigated the data are acquired with the technique of the online ensemble averaging in phase with the cell period; the phase averaging is performed, using as trigger signal the low-pass filtered static pressure at the casing upstream of the IGV while data are averaged over 200 cell passages. Once the acquisition frequency has been chosen, the number of points in one cell period depends upon cell frequency; as many as 800 points in a cell period have been acquired. Measurements have been performed in section e at 7 radial locations from hub to tip to reconstruct the flow upstream of the compressor while in the other 9 sections measurements have been performed only at midspan. The ensemble averaged acquisition is repeated for 12 different angular positions of the probe stem covering the $360^{\circ}$ rotation with a step of $30^{\circ}$.

Therefore, for each axial and radial position investigated 12 series of 800 points in one cell period are available both for the hot-wire and for the total pressure probe. The hotwire data acquired with the multirotation technique are then processed according to Puddu [12] to calculate the three velocity components and flow angles.

A similar procedure is used to process total pressure data. The flow is usually reconstructed using more than three independent measurements out of the 12 available from the multirotation acquisition. The solution, for each of the 800 measured points, is obtained with an iterative procedure and an error minimization process using the calibration curve of the probe. The angular calibration curve of the probe reports probe pressure coefficient in function of flow angle. The probe pressure coefficient is defined as difference between the true total pressure, and the measured pressure by the probe divided by the true dynamic pressure. The iterative procedure starts imposing a guess value of static pressure, total pressure and flow angle which are compared with the measured ones. The difference between the calculated and the measured pressure values allows the corrections of the unknown flow parameters that are iteratively modified in order to minimize the errors.

The measurement uncertainties given below correspond to the measurement performed with stationary flow conditions.

There is hot-wire velocity measurement.

(i) Mean velocity $\pm 2.5 \%$ of dynamic head.

(ii) Flow angle $\pm 2^{\circ}$.

(iii) Probe position $\pm 0.2 \mathrm{~mm}$.

There are pressure measurements.

(i) Pressure $\pm 2.5 \%$ of dynamic head.

The uncertainty will surely be higher in the interface regions of the flow, Puddu et al. [11], where the RMS of the measured cooling velocity increases significantly.

However, the high repeatability found in the measurements over the years of testing on the same machine supports the results and gives confidence in the trends reported and in the qualitative description of the kinematic structure of the cell.

\section{Presentation of Results}

As it has been discussed in the introduction, over the past 60 years different interpretations of the cell structure have been proposed. In the beginning the cell was thought of as 


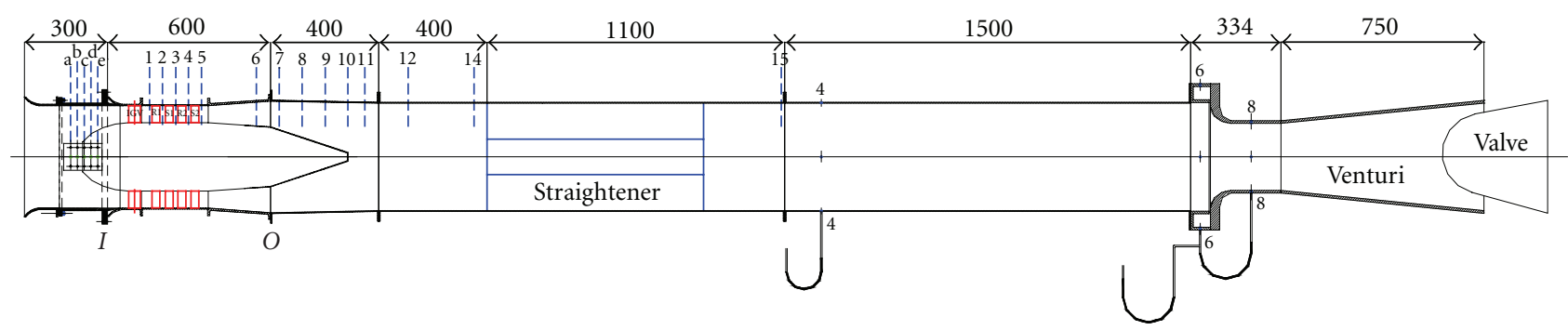

Figure 3: Two-stage compressor test facility.

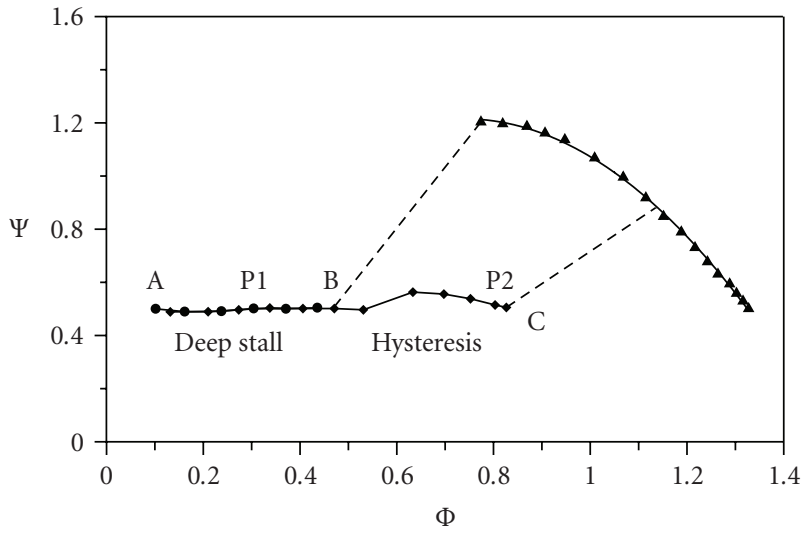

FIgURE 4: Compressor characteristic curve.

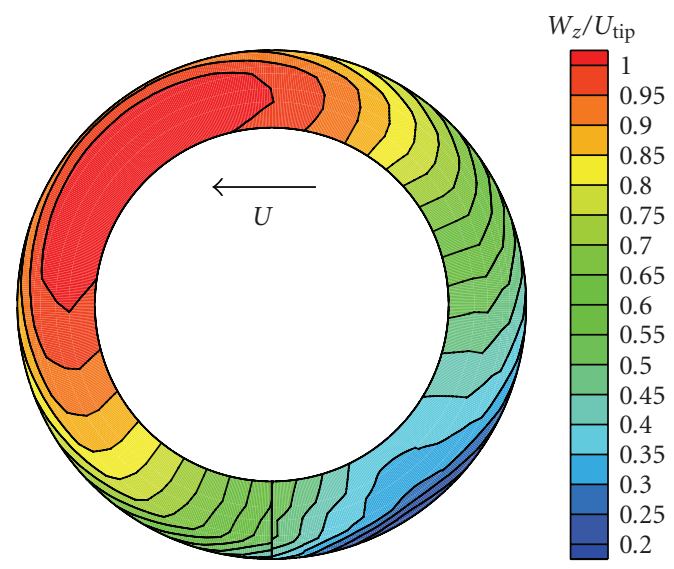

FIgURE 5: Axial flow component section e.

a sort of dead fluid body rotating around the annulus (Fabri [1]) while a new concept was proposed by Day and Cumpsty [2] named the active cell model. Seidel [3] even compared rotating stall with meteorological event. Rotating stall should be guided by the Rossby waves of the blade channels under the action of the baroclinic waves in the annular spaces between blade rows and the circular Karman vortex street around the circumference of the rotor. Breugelmans and Mathioudakis [8] have confronted both ideas [1,2] with their detailed experimental results and reached the conclusion, that the cell can show different aspects in common with both stall cell models.
The different ideas conceived in the past about the cell structure were a direct consequence of the interpretation of experimental data which, over the years, were available with increased quality and quantity. In this sense the present data are discussed in comparison with the previous theories and experimental results. Figure 5 shows the nondimensional axial velocity component in section e upstream of the IGV. One may notice that values are all positive, meaning that in this section there is not back flow. Nevertheless, the axial velocity component is not constant along the circumference; there is a perturbed flow region (blue colour) where the axial velocity component is smaller than that in the unperturbed "clean-flow" region (red colour). In Figure 6, the tangential velocity component in the cell reference frame is shown. One immediately notices that there is a wide region in red colour characterised by zero value of tangential velocity component. If the tangential velocity is zero in the cell reference frame it means that in the absolute reference frame the air particles are moving in the tangential direction with the same speed as the cell. This fact brings evidence of the presence of some fluid body which is actually rotating around the annulus at the same speed as the cell. However, this fluid rotating at cell's speed is far from being "dead," because it is characterised by positive values of axial velocity component which means that there is a mass flow entering the cell from upstream. This rotating "alive" fluid is also characterised by high values of absolute total pressure; see Figure 7. Considering that section $\mathrm{e}$ is upstream of the compressor, no moving blades, and that there is no back flow which could be responsible for a local increase of total pressure, this phenomenon is compatible with the unsteadiness of the absolute flow in presence of local velocity and static pressure gradients due to cell influence. Another interesting piece of information which can be drawn from the presented data is related to the axial velocity component; it can be seen that there is a region (colour blue Figure 5) with very low axial velocity component.

This region is also characterised by very high values of static pressure as shown in Figure 8 (red colour region). These last two flow field features are relevant to the issue of cell motion as it will be discussed further on. Moreover, in Figure 9, the data taken at midspan in different sections along the compressor axis are shown. A sketch of the compressor has been put on the side of the plot to visualise the position of the measuring sections along the test facility. The cell pattern has been reproduced twice in the circumferential direction in order to obtain a better description of the streamlines. 


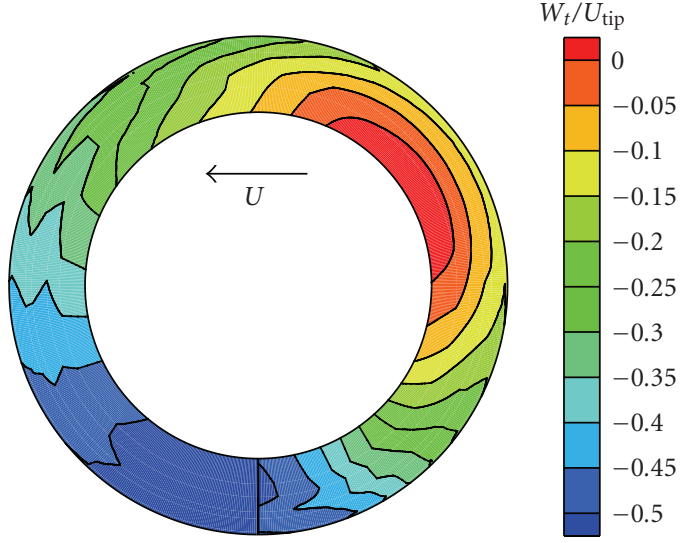

FIGURE 6: Tangential velocity component section e.

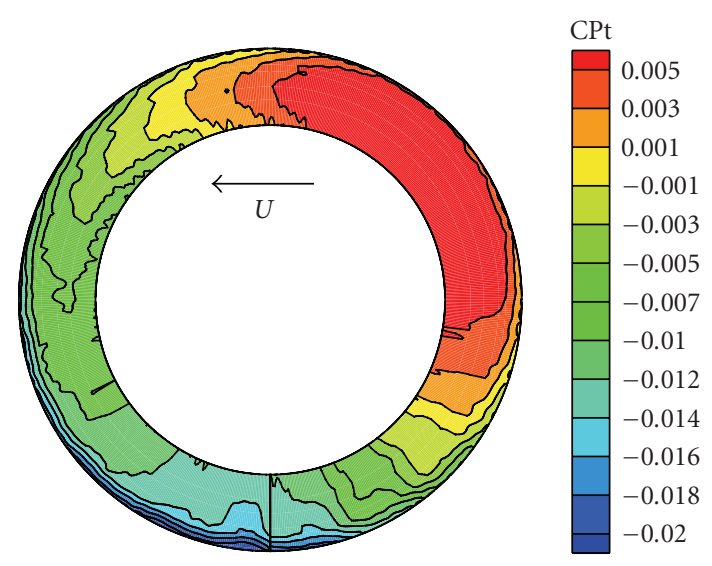

FIgURE 7: Total pressure coefficient section e.

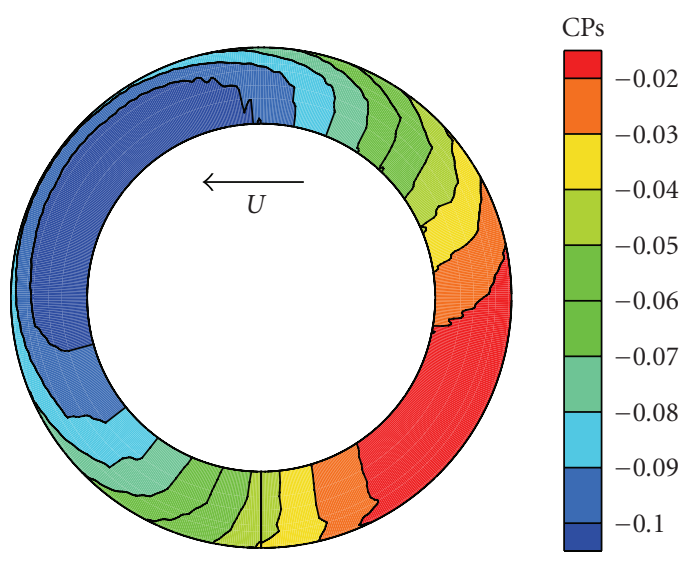

FIgURE 8: Static pressure coefficient section e.

The iso-velocity contour plots are showing a narrow range of values for the relative tangential velocity component so to highlight (green colour) the region characterised by particles which are travelling at cell speed in the absolute reference frame. One may see that this region extends well downstream of the compressor and that the overall perturbed flow region

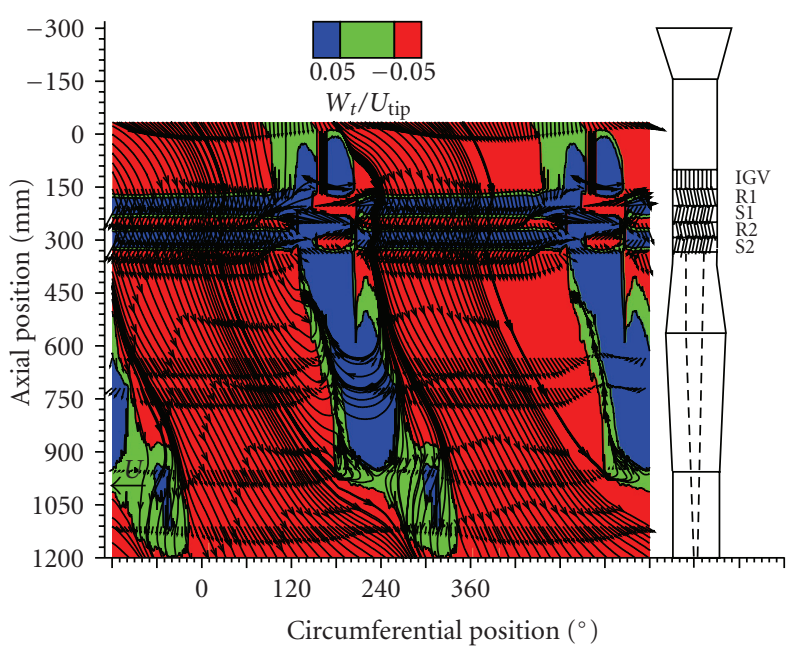

FIgURE 9: Relative tangential flow component at midspan.

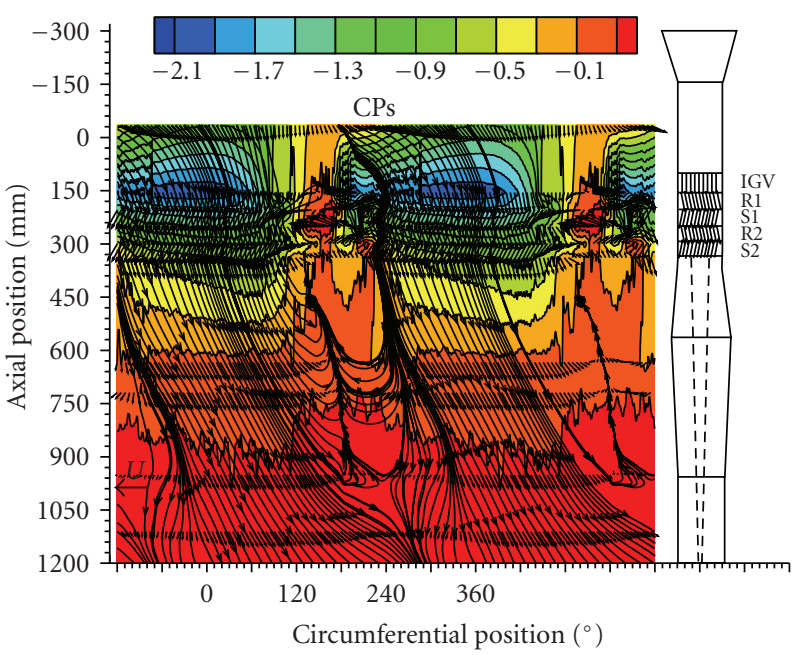

FIGURE 10: Static pressure coefficient at midspan.

is not precisely axial. This aspect further supports the idea of the cell seen as a rotating fluid body.

However, it is also clear that inside this region there is the presence of fluid particles with tangential velocity component greater than cell speed which was interpreted by Day and Cumpsty [2] as an active structure of cell due to the evidence of tangential crossing of flow. This fact calls for a better definition of cell boundaries so to better identify who is entering where. The qualitative streamlines plotted over the measured vector field with the aid of a graphic tool show that there is a "mainstream" which flows practically undisturbed and a region of deviation of the streamlines which is wider than the region with zero relative tangential velocity. It is also evident thatin Section 5, downstream of the second stator there is a wide region of back flow which is entering the compressor from the rear. This back flow will move across the stationary and rotating blade rows in an organised manner exchanging energy with it. In fact, high values of total pressure and kinetic energy are found 
upstream of both rotors in Section 1 and in Section 3 (Nurzia et al. [10] and 7 Puddu et al. [11]). In Figure 10 one may also notice that the centre of the cell is characterised by zero static pressure coefficient. In fact between the backflow region and the clean flow region the stalled-flow region has been identified (Puddu et al. [11]) which is the one changing its circumferential extension when the compressor's operating point moves along the stalled compressor performance curve (Palomba [13]). Therefore, as far as the blade rows are concerned the back flow will flow but it will have to cross a wide region characterised by high static pressure. The air coming from downstream into del compressor crosses the blade rows and crosses the cells in the back flow region, while presents almost zero axial flow component and very high tangential component compatible with blade row motions (both blade rows are moving in the cell reference frame) in the stalled flow region. Apparently in the stalled flow the through flow along the blade vanes is strongly reduced leading to these very high values of tangential velocity between the blade rows. Moreover, at the cell boundaries the values of tangential and axial velocity drop dramatically and this fact actually forbids the tangential crossing of the flow particles (one may notice the accumulation of streamlines at the cell border).

Therefore, one could think that the high values of tangential velocity are due to the blade row action on the flow and to the severe blockage of the blade vanes in the stalled flow region, like an internal redistribution of the flow. The cell is receiving flow from upstream and from downstream and this flow is wrapping itself around. The cell borders are characterised also by radial velocity component gradients and by sharp drops of total pressure coefficient. Therefore there is a tremendous dissipation taking place in the region where the clean flow and the stalled flow meet and where axial and tangential flow components are strongly reduced.

Although the stalled flow region and the backflow region extend nearly axially in the compressor the intermediate regions are less aligned in the axial direction. Moreover it is worthwhile to mention that while the stator's blades stall in the front of the cell and immediately enter the stalled region of the cell, the rotor blades stall in the rear of the cell and enter the back flow region. This could be at the origin of the tangential variation of the position of the intermediate region among stationary and rotating blade rows.

Lastly, there is one more aspect to consider which characterises rotating stall, namely, the origin of cell rotation. If the cell is considered as a rotating physical system exchanging mass and energy interacting with the main stream and the blade rows, to interpret its motion it is necessary to observe the static pressure field at its border in relationship with the velocity field. The experimental results clearly demonstrate that there is a strong circumferential gradient of static pressure where the cell is interacting with the blade rows. The clean flow is characterised by low static pressure while the back flow has high static pressure. Certainly this static pressure gradient is born with the establishment of the back flow which will cause the static pressure in the cell to reach the downstream values. This static pressure gradient is to be considered as one of the "motors" of the cell rotation.
It should also be recognised that moving downstream, away from the compressor, the circumferential static pressure gradient is reduced gradually and the cell flow appears as a wake behind a rotating body. This analysis of experimental results would not be complete if the effect of blade rows on rotation would not be taken into account. It is evident that the regions of high total pressure inside the cell are due to the rotor blades' action on the back flow. Clearly this effect will contribute to the one due to the static pressure gradients both of them in favour of the cell motion, while the stator's blades action clearly acts in the opposite direction reducing thus in the sense of slowing down the cell.

\section{Conclusions}

A detailed experimental investigation of three-dimensional flow field and pressure field during one cell full-span abrupt rotating stall in a two-stage axial-flow compressor has been conducted with the aid of a single slanted hot wire and the multirotation technique and of a total pressure probe.

This paper aimed at the investigation of the cell structure and motion through the interpretation of the whole flow field including far upstream and downstream of the blade rows. The experimental results have been discussed and compared with the previous results and interpretation of cell structure and the following conclusions were drawn.

(i) The cell shows a complex structure. While there are large elements of fluid particles rotating at the same speed as the perturbation the axial velocity component is not zero, therefore the rotating fluid body is far from being a "dead body."

(ii) Fluid particles are feeding the cell from upstream and downstream while a tangential crossing of flow does not seem to be possible at the interface regions.

(iii) Inside the cell there is a strong interaction between the blades and the flow; total pressure of particles crossing the rotor in reverse flow is increasing. In the cell reference frame, both stators and rotor blades are moving and interacting with the fluid particles arriving from the downstream duct. The blades action is also participating to the development of high values of tangential velocity component in the SF region.

(iv) The cell motion does not show the characteristic of a travelling wave due to the fact that particles have the same tangential velocity as the perturbation.

(v) There seem to be fluid particles entering the cell from upstream and therefore the cell is not just a passive obstruction of the crossing area and new models will have to be formulated to describe the rotating cell.

(vi) The results suggest that there is a static pressure field generated by the establishment of the back flow and the stalling of blades which could be responsible for cell rotation. Moreover, it is evident a great transfer of kinetic energy in the tangential direction imparted by rotor blades which is very likely participating in the cell rotation. 


\section{Nomenclature}

$\begin{array}{ll}\mathrm{C}: & \text { Absolute flow velocity } \\ \mathrm{CPs}=\left(\mathrm{P}_{\mathrm{S}}-\mathrm{P}_{\mathrm{TI}}\right) /\left(1 / 2 \rho U_{\text {tip }}^{2}\right): & \text { Static pressure coefficient } \\ \mathrm{CPt}=\left(\mathrm{P}_{\mathrm{T}}-\mathrm{P}_{\mathrm{TI}}\right) /\left(1 / 2 \rho U_{\text {tip }}^{2}\right): & \text { Total pressure coefficient } \\ \mathrm{P}: & \text { Pressure } \\ U_{\text {tip }}: & \text { Blade tip speed } \\ \mathrm{W}: & \text { Fluid velocity in cell } \\ & \text { reference frame } \\ \phi=\mathrm{C}_{\mathrm{a}} / \mathrm{U}_{\mathrm{t}}: & \text { Flow-rate coefficient } \\ \psi=\left(\mathrm{P}_{\mathrm{SO}}-\mathrm{P}_{\mathrm{TI}}\right) /\left(1 / 2 \rho U_{\text {tip }}^{2}\right): & \text { Total-to-Static pressure } \\ & \text { coefficient } \\ \rho: & \text { Fluid density }\end{array}$

\section{Subscripts}

z, t, r: Axial, tangential, radial directions

I: $\quad$ Compressor inlet

O: Compressor outlet

S: $\quad$ Static

T: Total

tip: Tip

\section{References}

[1] J. Fabri and R. Siestrunck, "Rotating stall in axial flow compressors," Journal of the Aeronautical Sciences, pp. 805812, 1957.

[2] I. J. Day and N. A. Cumpsty, "The measurement and interpretation of flow within rotating stall cells in axial compressors," Journal of Mechanical Engineering Sciences, vol. 20, no. 2, 1978.

[3] U. Seidel, "Rotating stall cell and von karman vortex steet a meteorological theory," in Axial Flow Compressors, Lecture Series 1992-2002, von Karman Institute for Fluid Dynamics, Rhode-Saint-Genèse, Belgium, 1992.

[4] H. W. Emmons, C. E. Pearson, and P. Grant, "Compressor surge and stall propagation," Transaction of the ASME, pp. 455-469, 1955.

[5] F. K. Moore, "A theory of rotating stall of multistage axial compressors-part I: small disturbances—part II: finite disturbances_-part III: limit cycles," Journal of Engineering for Gas Turbines and Power, vol. 106, no. 2, pp. 313-336, 1984.

[6] F. K. Moore and E. M. Greitzer, "A theory of post stall transients in axial compression systems-part 1: development of equations," Journal of Turbomachinery, vol. 108, pp. 68-76, 1986.

[7] D. K. Das and H. K. Jiang, "An experimental study of rotating stall in a multistage axial flow compressor," Journal of Engineering for Gas Turbines and Power, vol. 106, no. 3, pp. 542-551, 1984.

[8] F. A. E. Breugelmans and K. Mathioudakis, "The three dimensional flow field inside an axial flow compressor operating in rotating stall," in Proceedings of the 7th ISABE Conference, pp. 726-733, 1985.

[9] C. Palomba, P. Puddu, and F. Nurzia, "3D flow field measurement around a rotating stall cell," in Proceedings of the 43rd International Gas Turbine \& Aeroengine Congress \& Exhibition, Stockholm, Sweden, June 1998, ASME 98-GT-596.

[10] F. Nurzia, C. Palomba, and P. Puddu, "Experimental investigation of stall in a two-stage compressor," in Proceedings of the ASME Turbo Expo, Monaco, Spain, June 2000, ASME 2000GT-571.
[11] P. Puddu, C. Palomba, and F. Nurzia, "Comparison of pressure and velocity measurements during one cell rotating stall," in Proceedings of the MIS-MAC VII, pp. 39-48, Cagliari, Italy, April 2001.

[12] P. Puddu, "Misure di turbolenza in elementi fissi e rotanti di turbomacchine con l'impiego di sonde a filo caldo," in MISMAC IV, Trieste, Italy, 1993.

[13] C. Palomba, "Analysis of local flow structure and global compressor performance during rotating stall," in Proceedings of the ASME Turbo Expo, vol. 5, pp. 537-544, Vienna, Austria, June 2004, GT2004-53816. 

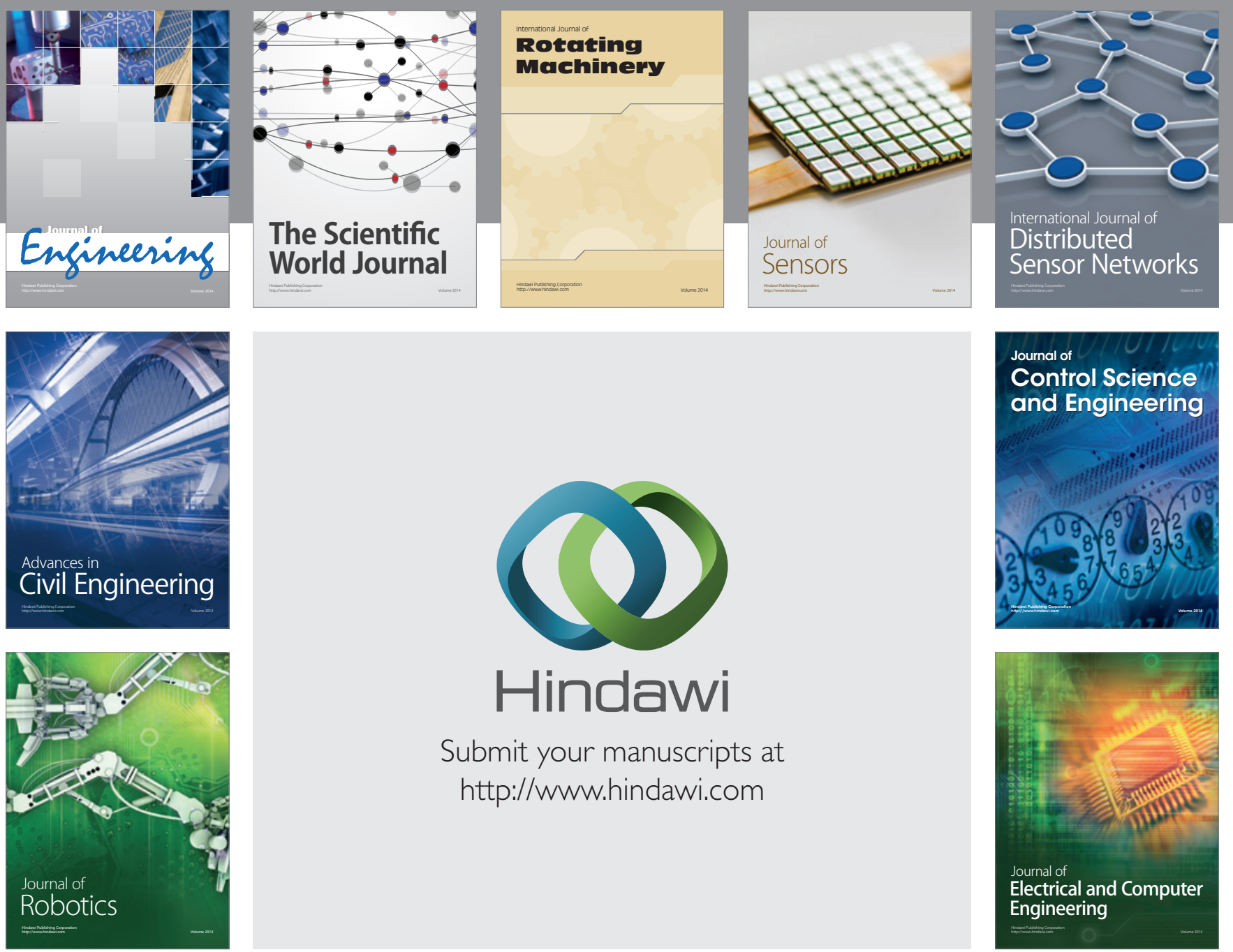

Submit your manuscripts at

http://www.hindawi.com
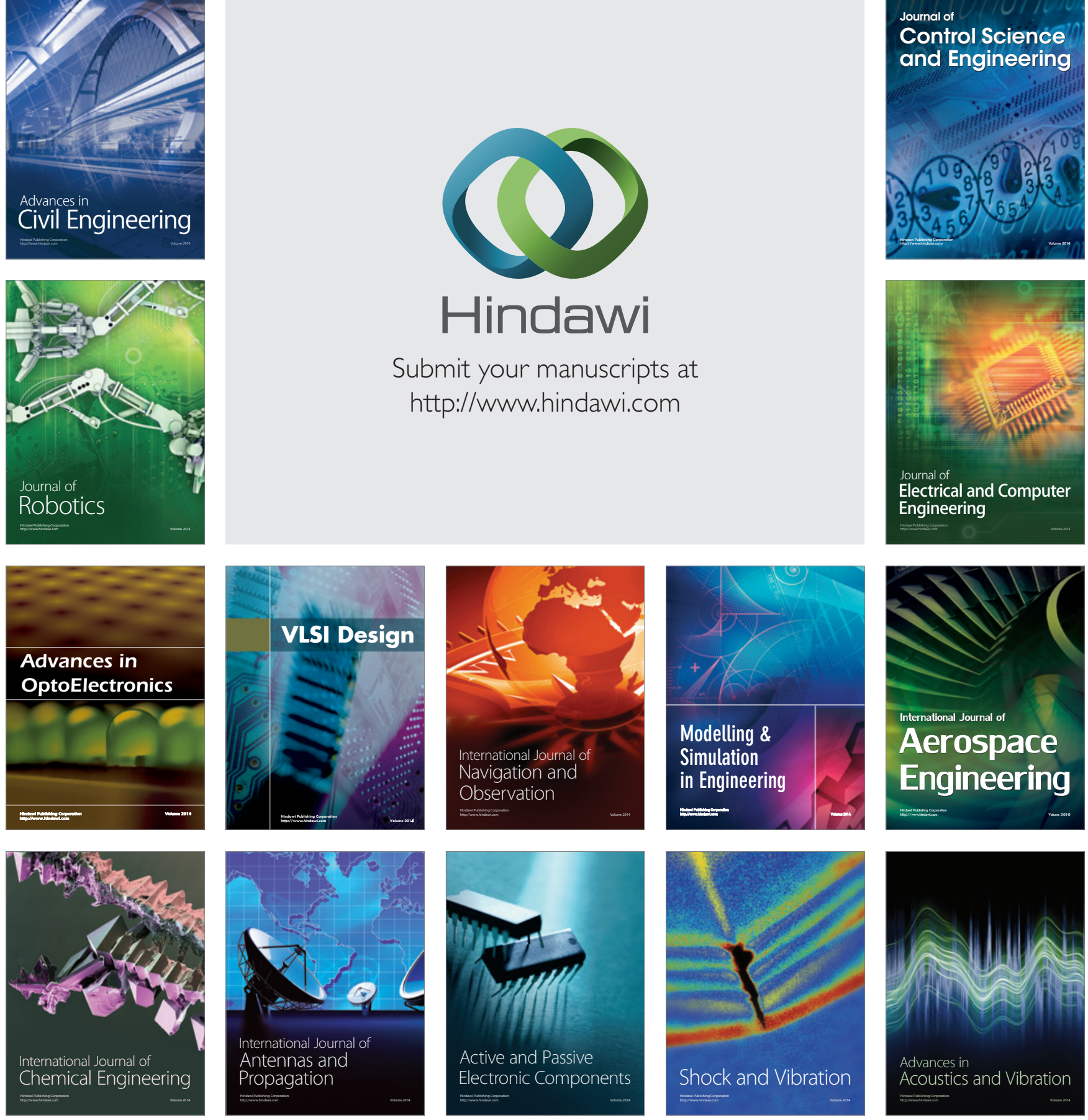